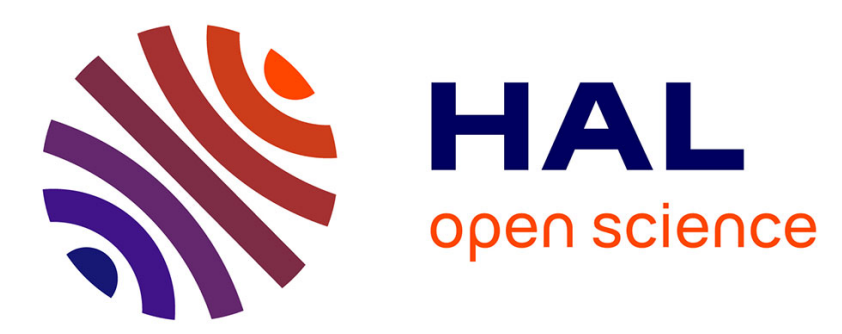

\title{
Induction Motor Stator Faults Diagnosis by a Current Concordia Pattern Based Fuzzy Decision System
}

Fatiha Zidani, Mohamed Benbouzid, Demba Diallo, Mohamed-Saïd Naït-Saïd

\section{To cite this version:}

Fatiha Zidani, Mohamed Benbouzid, Demba Diallo, Mohamed-Saïd Naït-Saïd. Induction Motor Stator Faults Diagnosis by a Current Concordia Pattern Based Fuzzy Decision System. IEEE Transactions on Energy Conversion, 2003, 18 (4), pp.469-475. hal-01052445

\section{HAL Id: hal-01052445 https://hal.science/hal-01052445}

Submitted on 26 Jul 2014

HAL is a multi-disciplinary open access archive for the deposit and dissemination of scientific research documents, whether they are published or not. The documents may come from teaching and research institutions in France or abroad, or from public or private research centers.
L'archive ouverte pluridisciplinaire HAL, est destinée au dépôt et à la diffusion de documents scientifiques de niveau recherche, publiés ou non, émanant des établissements d'enseignement et de recherche français ou étrangers, des laboratoires publics ou privés. 


\title{
Induction Motor Stator Faults Diagnosis by a Current Concordia Pattern Based Fuzzy Decision System
}

\author{
Fatiha Zidani, Mohamed Benbouzid, Senior Member, IEEE, \\ Demba Diallo, Member, IEEE and Mohamed S. Naït-Saïd
}

\begin{abstract}
This paper deals with the problem of detection and diagnosis of induction motor faults. Using the fuzzy logic strategy, a better understanding of heuristics underlying the motor faults detection and diagnosis process can be achieved. The proposed fuzzy approach is based on the stator current Concordia patterns. Induction motor stator currents are measured, recorded and used for Concordia patterns computation under different operating conditions, particularly for different load levels. Experimental results are presented in terms of accuracy in the detection motor faults and knowledge extraction feasibility. The preliminary results show that the proposed fuzzy approach can be used for accurate stator fault diagnosis if the input data are processed in an advantageous way, which is the case of the Concordia patterns.
\end{abstract}

Index Terms-Induction motor, fault detection, diagnosis, fuzzy logic, stator currents, Concordia pattern.

\section{INTRODUCTION}

There are many published techniques and many commercially available tools to monitor induction motors to ensure a high degree of reliability [1]. One of the most widely used techniques to obtain information on the health state of induction motors is based on the processing of the stator line current [2]. Typically, in the motor fault diagnosis process, sensors are used to collect time domain current signals. In recent years, the monitoring and fault detection of electrical machines have moved from traditional methods to artificial intelligence techniques (i.e. neural networks, fuzzy logics, and genetic algorithms). Such techniques require a minimum of intelligent configuration since no detailed analysis of the fault mechanism is necessary and no system modeling is required [3].

As experienced engineers often need to interpret frequently inconclusive measurement data, a fuzzy logic approach could be helpful in the handling of this kind of data to achieve a diagnosis task (e.g. detection of induction motor faults). In fact, fuzzy logics is reminiscent of human thinking processes and of natural language, enabling decisions to be made based on vague information.

F. Zidani and M.S. Nait-Said are with the Electrical Engineering Department, University of Batna, Algeria.

M.E.H. Benbouzid and D. Diallo are with the Centre de Robotique, d'Electrotechnique et d'Automatique (CREA) of the University of Picardie Jules Verne at Amiens, 7, Rue du Moulin Neuf, 80000 Amiens, France (email: m.benbouzid@ieee.org; ddiallo@ieee.org).
Moreover, a fuzzy logic based system allows the transformation of heuristic terms into numerical values via fuzzy rules and membership functions. It is also able to approximate the complex relationship related to a diagnosis task. Fuzzy logics allows items to be described as having a certain membership degree in a set [4]. When conducting fault diagnosis, several situations may occur in which an object is not obviously "good" or "bad", but may fall in between [5-7]. Considering that the interpretation of the condition of the induction motor is a fuzzy concept [8], researchers have proposed some fuzzy logic based diagnosis approaches in the past few years [9-22]. A major difficulty was the lack of appropriate processing of the fuzzy input data.

This paper then describes the application of a fuzzy logic approach to the diagnosis of induction motor stator and phase conditions [23]. The proposed fuzzy approach is based on the stator current Concordia patterns. It uses pattern errors to overcome the effect of time-varying loads on the diagnosis process [24-25]. Experimental results on a 4-kW squirrel-cage induction motor are presented in terms of fault detection accuracy and knowledge extraction feasibility to highlight the generality of the proposed diagnosis approach.

\section{THE CONCORDIA VECTOR APPROACH}

In three-phase induction motors, the connection to the mains does not usually use the neutral. Therefore, the mains current has no homopolar component. A two dimensional representation can then be used to describe three-phase induction motor phenomena. A suitable two dimensional representation is based on the current Concordia vector; sometimes erroneously called Park vector [26-27].

The current Concordia vector components $\left(I_{\alpha}, I_{\beta}\right)$ are a function of mains phase variables $\left(I_{a}, I_{b}, I_{c}\right)$ as:

$$
\left\{\begin{array}{l}
I_{\alpha}=\sqrt{\frac{2}{3}} I_{a}-\frac{1}{\sqrt{6}} I_{b}-\frac{1}{\sqrt{6}} I_{c} \\
I_{\beta}=\frac{1}{\sqrt{2}} I_{b}-\frac{1}{\sqrt{2}} I_{c}
\end{array}\right.
$$

In ideal conditions, three-phase currents lead to a Concordia vector with the following components: 


$$
\left\{\begin{array}{l}
I_{\alpha}=\frac{\sqrt{6}}{2} I_{M} \sin \omega_{s} t \\
I_{\beta}=\frac{\sqrt{6}}{2} I_{M} \sin \left(\omega_{s} t-\frac{\pi}{2}\right)
\end{array}\right.
$$

Where $I_{M}$ is the supply phase current maximum value and $\omega_{s}$ is the supply frequency.

The current Park components are calculated by the following expression:

$$
\left[\begin{array}{l}
I_{d} \\
I_{q}
\end{array}\right]=\left[\begin{array}{cc}
\cos \theta_{s} & \sin \theta_{s} \\
-\sin \theta_{s} & \cos \theta_{s}
\end{array}\right]\left[\begin{array}{c}
I_{\alpha} \\
I_{\beta}
\end{array}\right]
$$

Where $\theta_{s}=\omega t_{s}$ represents the angle between the stator and the rotating reference frames. In a steady state, the current Park components are dc values and the locus in the $d-q$ plane is a point (Fig. 1a) [28].

$$
\left\{\begin{array}{l}
I_{d}=0 \\
I_{q}=\frac{\sqrt{6}}{2} I_{M}
\end{array}\right.
$$

On the contrary, the current Concordia vector is a circular pattern centered on the origin of the coordinates as shown in Fig. 1b. Due to language misuse, the Concordia vector is sometimes called Park vector. This is a very simple reference figure that allows the detection of abnormal conditions by monitoring the deviations of acquired patterns.

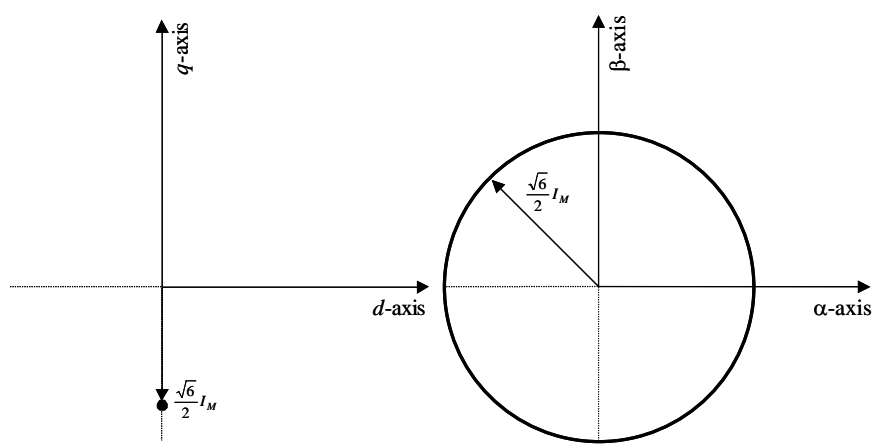
(a) Park pattern (point).
(b) Concordia pattern (circle)

Fig. 1. Current patterns for ideal conditions.

\section{EXPERIMENTAL SETUP AND AVAILABLE DATA}

\section{A. Description of the Experimental Setup}

Figures 2 and 3 illustrate the experimental setup. It consists in a $4 \mathrm{~kW}, 220 / 380 \mathrm{~V}, 15 / 8.6 \mathrm{~A}, 50 \mathrm{~Hz}, 4$ poles, $\Delta$ connected squirrel-cage induction motor. A mechanical load is provided by a separate dc generator feeding a variable resistor. In order to allow tests to be performed at different load levels, the dc excitation current and the load resistor are both controllable.

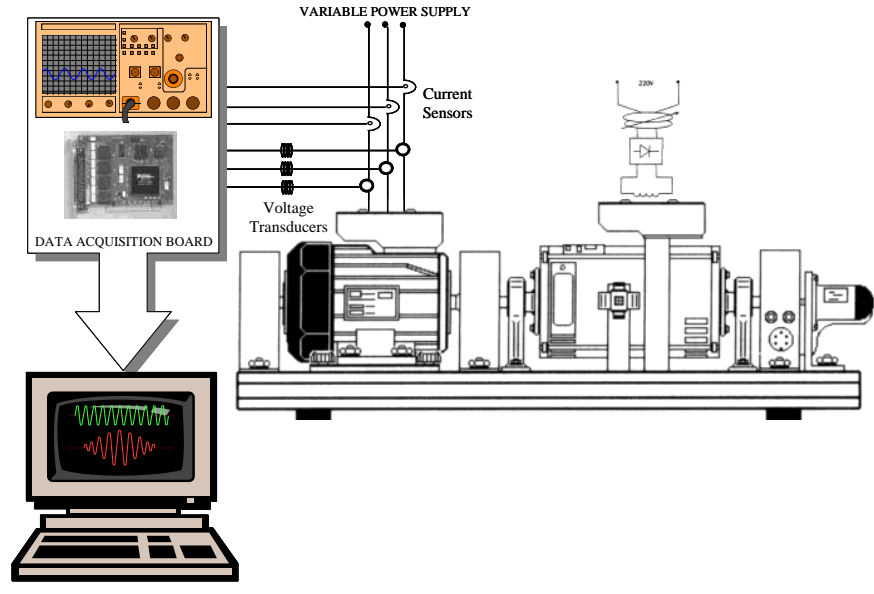

Fig. 2. Structure of the experimental setup.

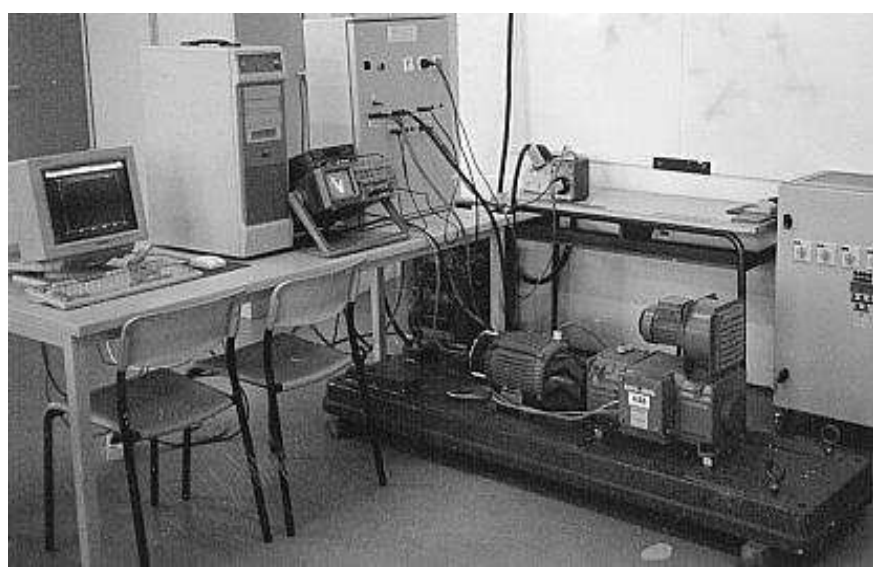

Fig. 3. View of the experimental setup.

The stator currents are sampled with a $1 \mathrm{kHz}$ sampling rate and interfaced to a computer by a data acquisition board.

\section{B. Available Experimental Data}

The induction motor has been initially operated without faults in order to determine the reference current Concordia pattern corresponding to the supposed healthy motor (Fig. 4). This pattern differs slightly from the expected circular one, because the supply voltage is not exactly sinusoidal. Then, two kinds of experiments have been carried out. In the first one, stator voltages were unbalanced by adding a 0.2 p.u. resistance to one phase. The second experiment has concerned a stator open phase effect. The current Concordia patterns corresponding to these faulty conditions are shown in Fig. 4. The occurrence of a voltage unbalance or of an open phase manifest themselves in the deformation of the current Concordia pattern corresponding to a healthy condition. This deformation leads to an elliptic pattern whose major axis orientation is associated to the faulty phase. 


\section{THE FUZZY DIAGNOSIS APPROACH}

Fuzzy systems rely on a set of rules. These rules, while superficially similar, allow the input to be fuzzy, i.e. more like the way humans tend to express their way of thinking. Thus, a power engineer might refer to an electrical machine as "somewhat secure" or a "little overloaded". This linguistic input can be expressed directly by a fuzzy system. Therefore, the natural format greatly eases the interface between the engineer's knowledge and the domain expert. Furthermore, infinite graduations of truth are allowed, a characteristic that accurately mirrors the real world, where decisions are seldom "crisp" [4].

Figure 5 schematically summarizes the fuzzy logic based diagnosis approach.

\section{A. Design of the Fuzzy Fault Detector}

The practical implementation of the Fuzzy Fault Detector (FFD), using the Concordia pattern, is shown in Fig. 6. The fuzzy diagnosis procedure is based on a suitable set of fuzzy rules, carried out both from the induction motor knowledge and the experiments (Fig. 4).
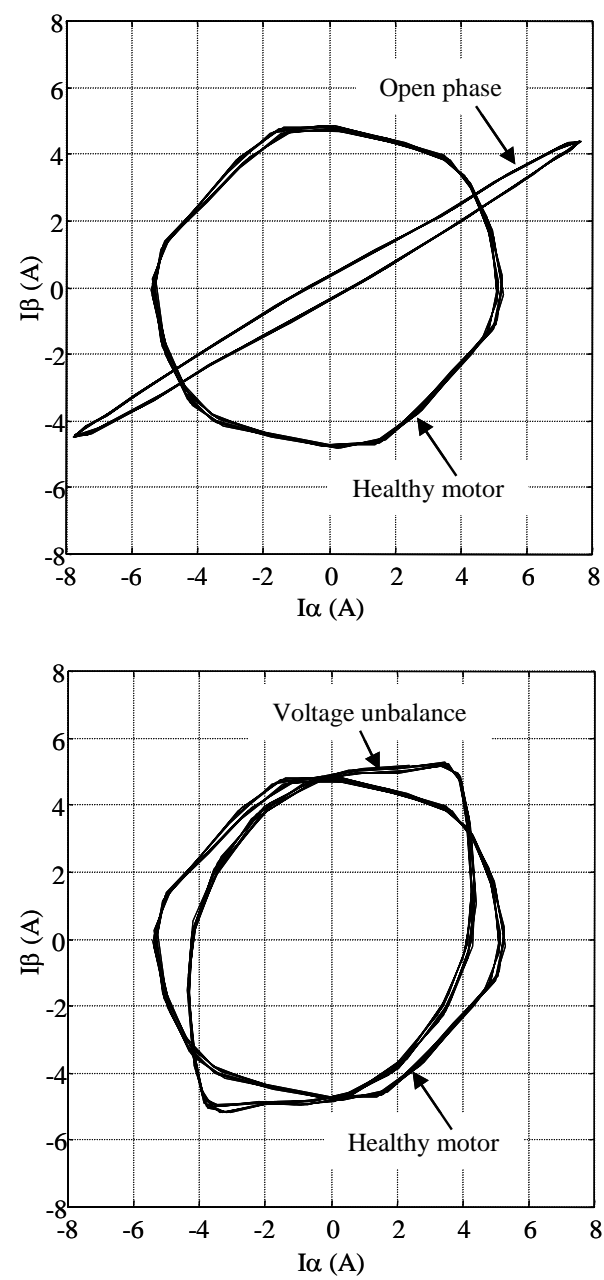

(a) Unloaded motor.
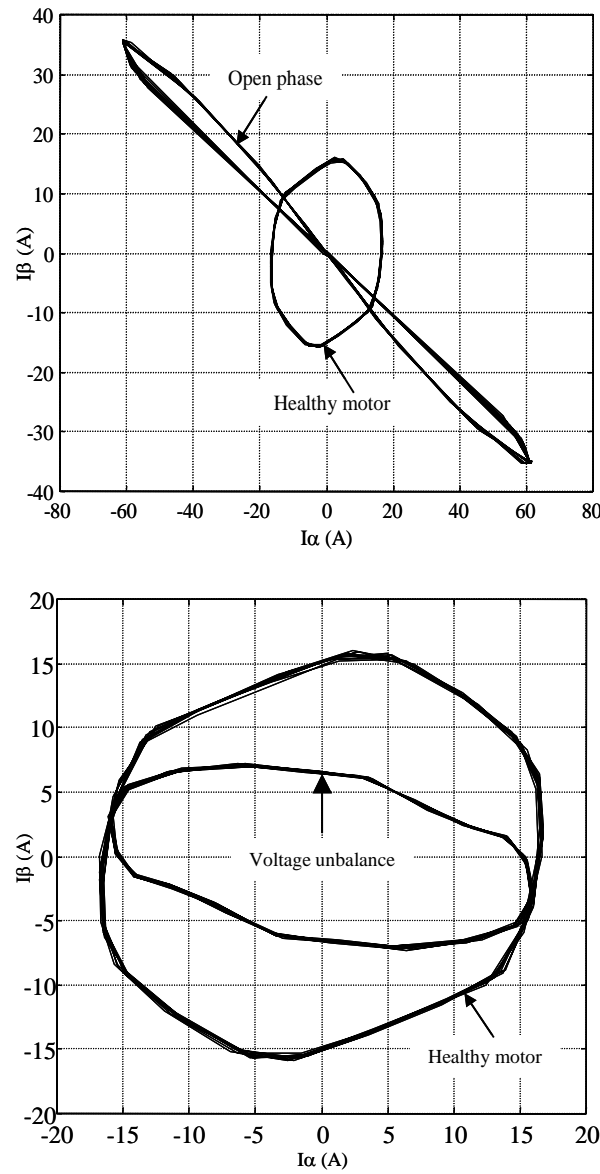

(b) Loaded motor.

Fig. 4. Induction motor stator current Concordia patterns.

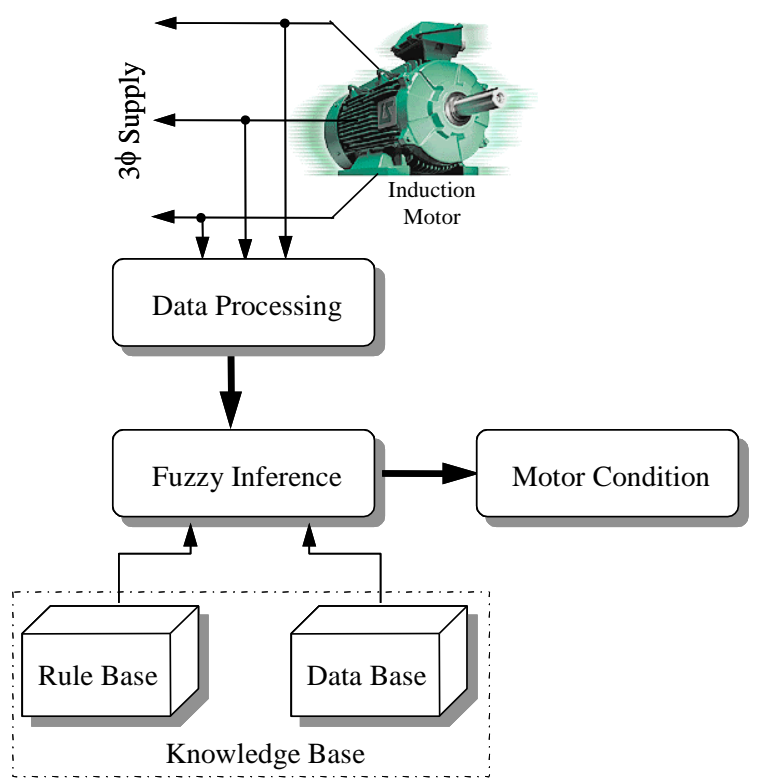

Fig. 5. Scheme of the fuzzy based diagnosis approach. 


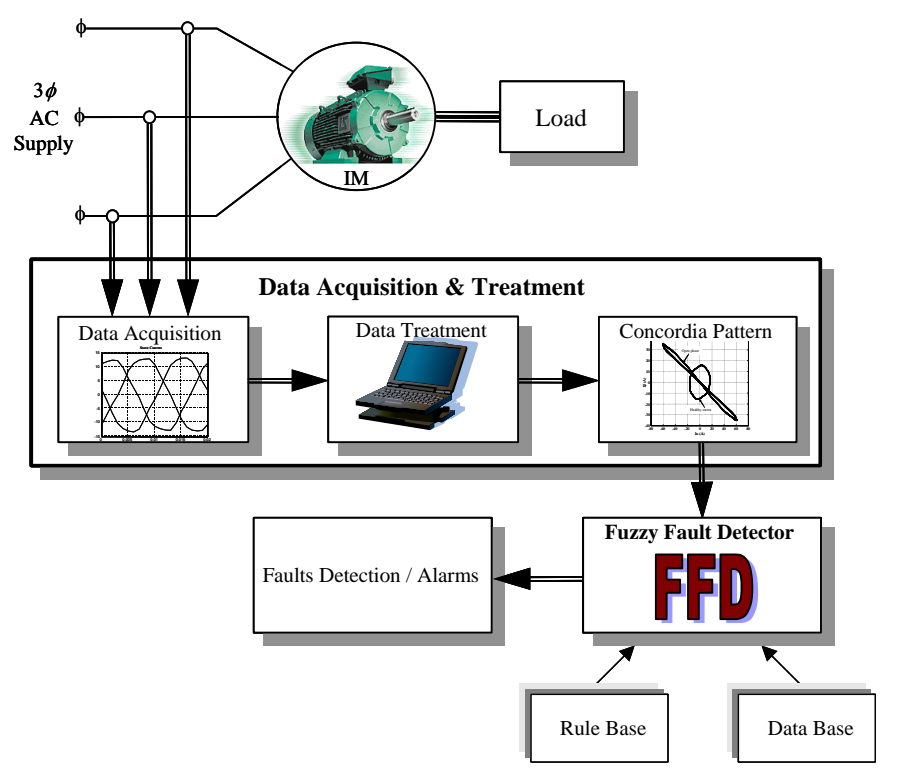

Fig. 6. Practical implementation of the fuzzy fault detector.

1) Input-output variables. In this work, stator current Concordia patterns of healthy and faulty motor are used to compute the FFD input variables. These are defined as follows

$$
\left\{\begin{array}{l}
e_{1}(k)=P_{h}(k)-P_{f}(k) \\
e_{2}(k)=e_{1}(k)-e_{1}(k-1)
\end{array}\right.
$$

Where $P_{h}$ is the healthy motor stator current Concordia pattern "Healthy Pattern" that is considered as the reference. $P_{f}$ is the faulty motor Concordia pattern or "faulty Pattern". It is variable with operating conditions. For simplicity, only Negative $(N)$, Zero $(Z)$, and Positive $(P)$ labels are considered for the input variables. Input variable $e_{2}$ gives accurately the threshold between healthy and faulty conditions.

With the proposed Fuzzy Fault Detector, there is no consideration of the diagnosis sensitivity to measurement errors. In fact, the use of these input variables (error signals) reduces the influence of measurement errors and therefore increases the robustness of the proposed approach against the system uncertainties.

When an abnormality develops in the drive system, the induction motor current, torque and speed are typically affected in a periodic manner [1]. In the case of periodic disturbances, all three-line currents $I_{a}, I_{b}$, and $I_{c}$ are simultaneously modulated with the fundamental frequency $f_{0}$ of the fault-induced oscillation of motor variables [29]. The value of the modulation depth (modulation index $m$ ) depends on the severity of the abnormality [30]. For the purpose of this study, the FFD output is modulation index severity $m s$ (severity index) that should be able to assess the fault severity. In terms of linguistics variables, four conditions are taken for this variable: Zero $(Z)$, Light $(L)$, Medium $(M)$, and $\operatorname{High}(H)$.
For the input-output fuzzy sets, the membership functions are centered on suitable point and have been chosen as shown in Fig. 7.

2) Extracted knowledge. Once the membership function forms have been determined, the fuzzy if-then rules can be derived. The list of the extracted rules is given in Table 1 . The rules are observed to be in agreement with the working principle of the system.

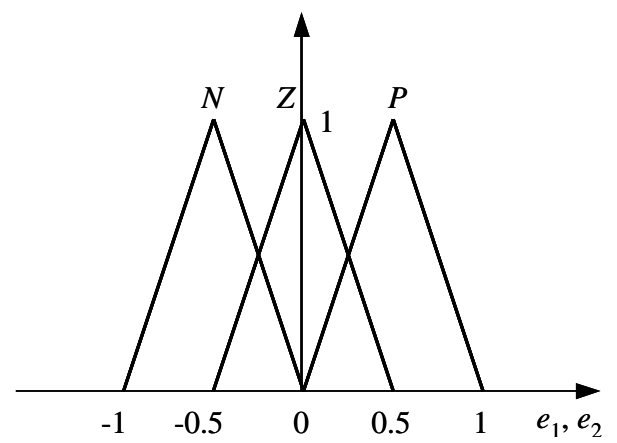

(a) Input variables.

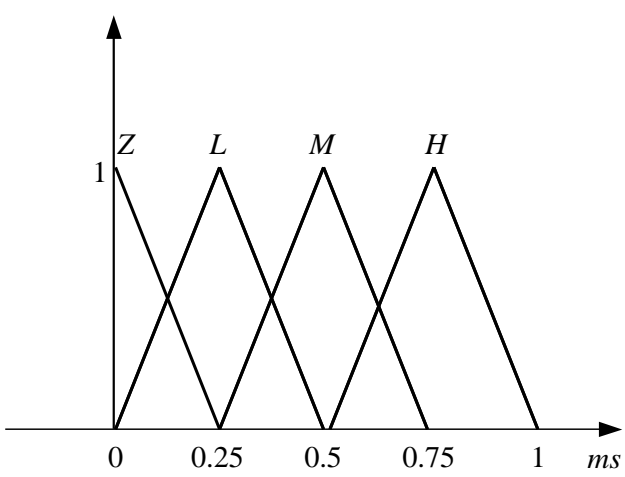

(b) Output variable

Fig. 7. Membership functions.

Table 1. Linguistic Rules.

\begin{tabular}{|c|c|c|}
\hline \hline If $e_{1}$ is & and $e_{2}$ & Then $m s$ is \\
\hline \hline$N$ & $N$ & $M$ \\
\hline$Z$ & $N$ & $L$ \\
\hline$P$ & $N$ & $M$ \\
\hline$N$ & $Z$ & $H$ \\
\hline$Z$ & $Z$ & $Z$ \\
\hline$P$ & $Z$ & $M$ \\
\hline$N$ & $P$ & $H$ \\
\hline$Z$ & $P$ & $L$ \\
\hline$P$ & $P$ & $H$ \\
\hline \hline
\end{tabular}

As an illustration:

- If ( $e_{1}$ is $N$ and $e_{2}$ is $P$ ) Then $m s$ is $H$ : This extracted rule suggests that when the error between a healthy pattern 
and a faulty one is negative and if this error increases, the output will apply a high severity index. This case corresponds in our experiment to an open phase for a loaded motor.

- If ( $e_{1}$ is $P$ and $e_{2}$ is $N$ ) Then $m s$ is $M$ : When the error between a healthy pattern and a faulty one is positive and if this error decreases, the output will apply a medium severity index. The fault severity is less significant than in the above situation In fact, this case corresponds in our experiment to a voltage unbalance of a loaded motor.

- If $\left(e_{1}\right.$ is $Z$ and $e_{2}$ is $P$ or $\left.N\right)$ Then $m s$ is $L$ : Both patterns are equal but the error may increase or decrease. In this case, the output will apply a light severity index that indicates the presence of an incipient fault.

These rules constitute one of the important improvements brought by the proposed approach according to the previously published works, even the neural networks approach [27] or the fuzzy one [22]. In fact, the proposed diagnosis scheme addresses the problem of fault detection in presence of an oscillating or position-varying load torque.

\section{B. Application and Results Analysis}

Figure 8 shows the FFD output (severity index $m s$ ) in different operating and load conditions.

Figure 8a shows the FFD output (severity index) in the case of the induction motor running at no load and in normal conditions. It was theoretically predicted that, in normal circumstances, the severity index would be Zero $(m s=Z)$. That is also the case for a loaded motor as it is shown by Fig. $8 \mathrm{~b}(m s=Z)$. The FFD was then tested in the case of a faulty motor. It is clear that the severity index increases not only with the occurrence of a fault (Fig. 8c $-m s=L$ ) but also depending on its severity (Fig. 8e and Fig. 8c). It is clear that an open phase is less severe than a voltage unbalance for an unloaded motor. Furthermore, the severity index is a good indicator to evaluate the influence of the motor load level on the occurred fault (Figs. 8d and 8f). For a loaded motor, an open phase is more severe (has a higher impact on the motor) than a voltage unbalance. Figure 9 shows the evolution of the values assumed by the severity factor according to the different tests carried out.

These tests put into evidence that the FFD is a suitable diagnosis tool not only to detect the occurrence of a fault but also its severity. This fact is due to the choice of the severity index in terms of linguistic variables to monitor the motor condition.

\section{Discussion}

The proposed diagnosis method could be applied to any type of induction motors (small to high power motors). In fact, we just need to adapt the Fuzzy Fault Detector (FFD) normalization gains of the input-output universe of discourse to the motor power [8]. Moreover, the power supply quality will affect the pattern shape (e.g. hexagonal shape for a square-wave voltage supply) but the proposed approach that relies upon the difference between a healthy and a faulty pattern will still be valid.

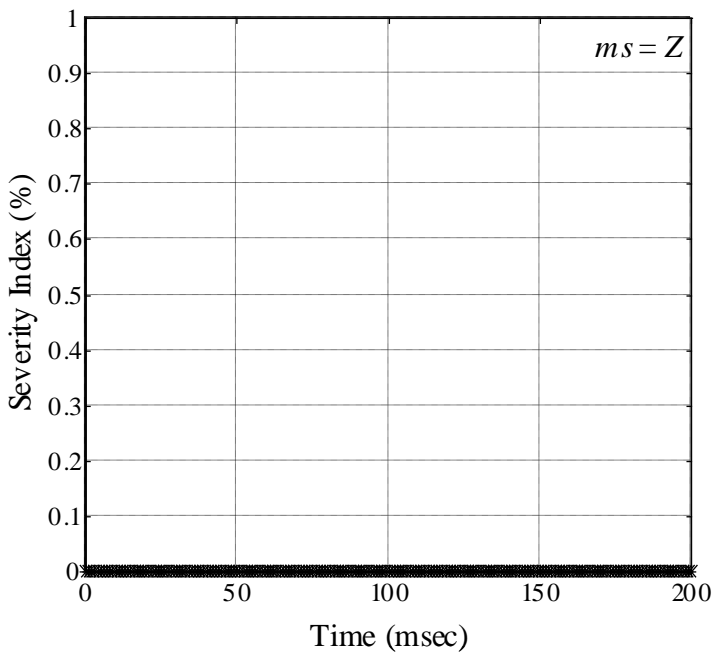

(a) Healthy unloaded motor.

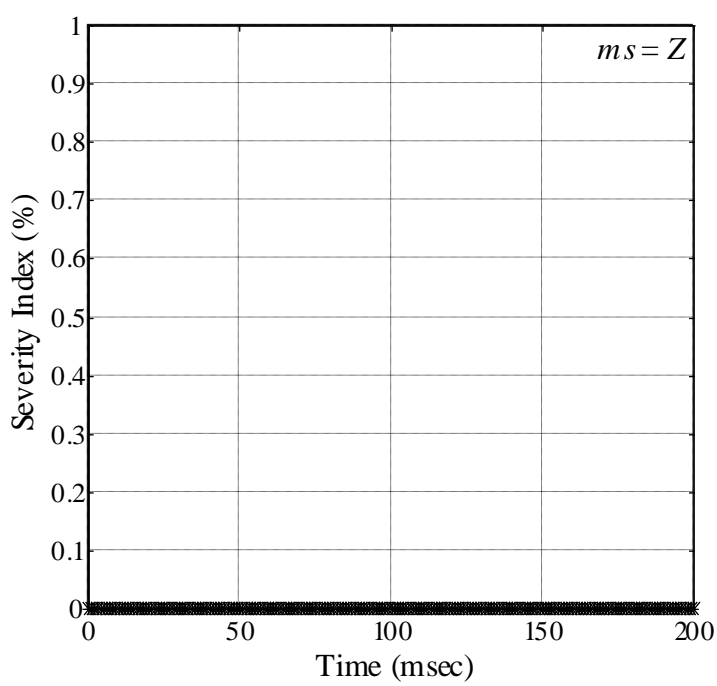

(b) Healthy loaded motor.

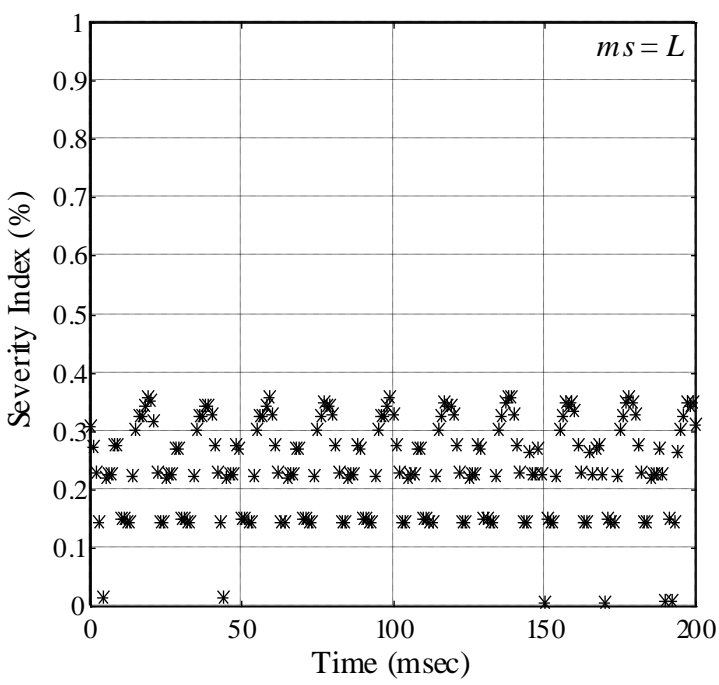

(c) Voltage unbalance - unloaded motor. 


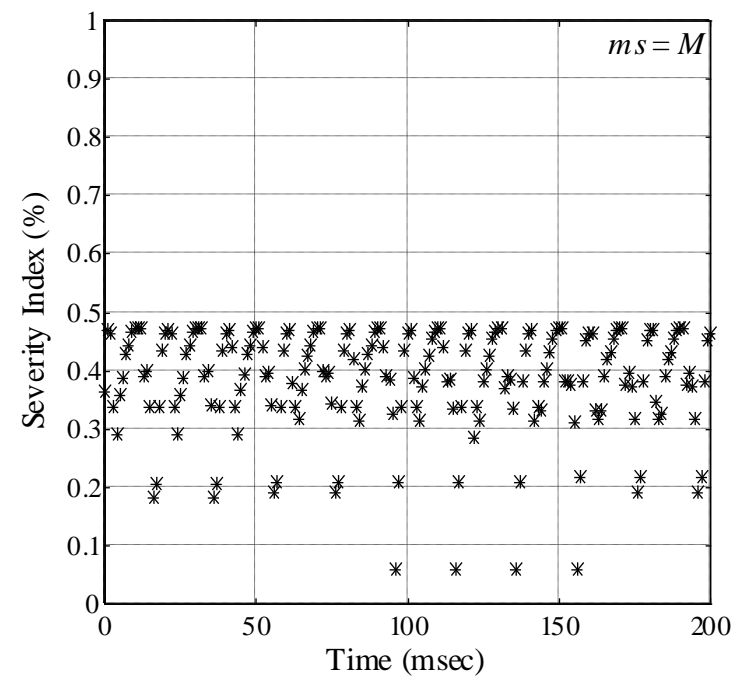

(d) Voltage unbalance - loaded motor.

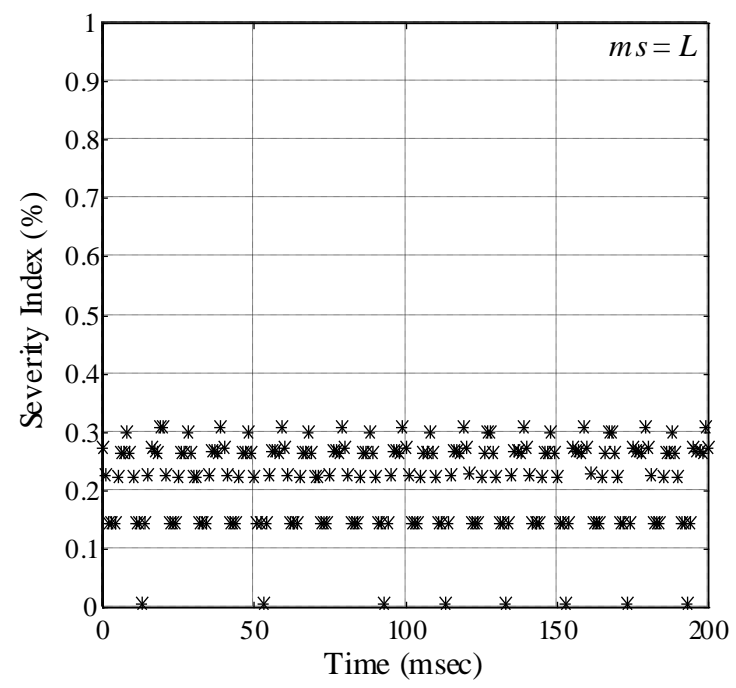

(e) Open phase - unloaded motor.

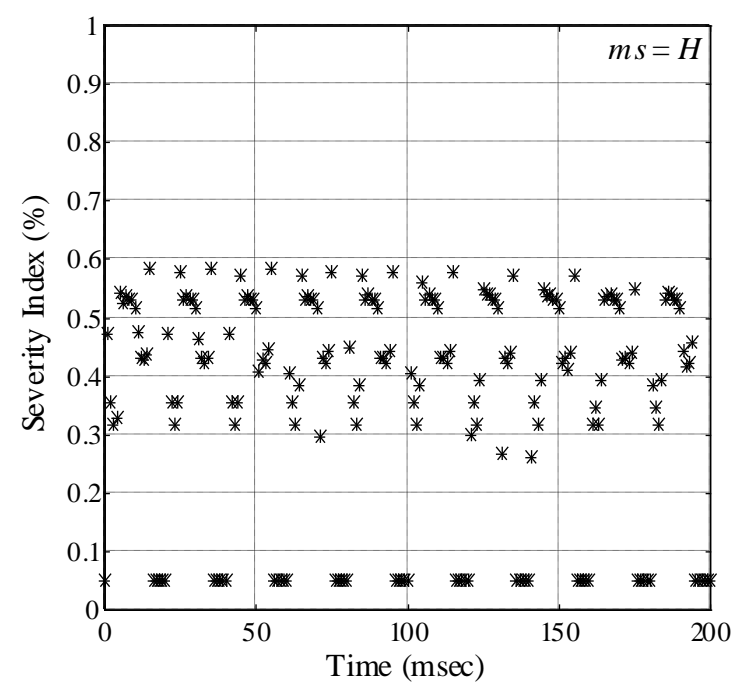

(f) Open phase - loaded motor.

Fig. 8. FFD output $(m s)$ for different operating and load conditions.

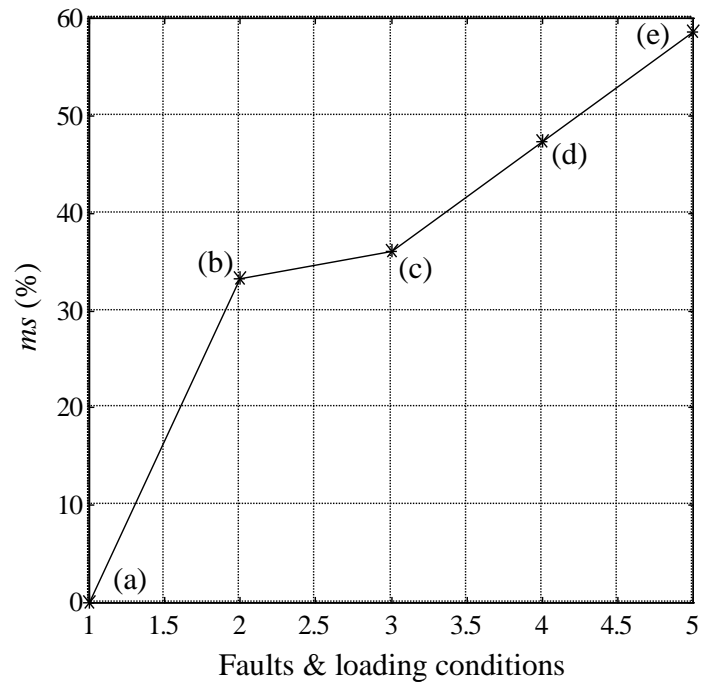

(a): max of Figs. 8a and 8b, (b): max of Fig. 8e, (c): max of Figs. 8c, (d): max of Fig. 8d, (e): max of Fig. 8f.

Fig. 9. Severity index evolution according to faults and loading conditions.

\section{CONCLUSIONS}

This paper is concerned by the problem of the detection and the diagnosis of induction motor faults. The proposed fuzzy approach is based on the stator current Concordia patterns. Induction motor stator currents have been measured, recorded and used for Concordia patterns computation under different operating conditions, particularly for different load levels. In fact, the proposed diagnosis approach addresses the problem of fault detection in presence of an oscillating or position-varying load torque.

Experimental results have been presented in terms of motor fault detection accuracy and knowledge extraction feasibility. These results clearly indicate that the proposed fuzzy approach is able to diagnose not only the fault in case but also its severity. Moreover, it has been proved that this approach is both accurate and easy-to-implement.

The proposed diagnosis method could be applied to any type of induction motors (small to high power motors). In fact, we just need to adapt the Fuzzy Fault Detector (FFD) normalization gains of the input-output universe of discourse to the motor power. Moreover, the power supply quality will affect the pattern shape (e.g. hexagonal shape for a squarewave voltage supply) but the proposed approach that relies upon the difference between a healthy and a faulty pattern will still be valid.

\section{ACKNOWLEDGMENTS}

The authors would like to thank the anonymous reviewers for their many important comments and suggestions. They also would like to thank L. Guyot from IUP GEII Amiens for the text review. 


\section{REFERENCES}

[1] M.E.H. Benbouzid, "Bibliography on induction motors faults detection and diagnosis," IEEE Trans. Energy Conversion, vol. 14, $\mathrm{n}^{\circ} 4$, December 1999, pp. 1065-1074.

[2] M.E.H. Benbouzid, "A review of induction motors signature analysis as a medium for faults detection," IEEE Trans. Industrial Electronics, vol. 47, n5, October 2000, pp. 984-993.

[3] F. Filippetti et al., "Recent developments of induction motor drives fault diagnosis using AI techniques," IEEE Trans. Industrial Electronics, vol. 47, n5, October 2000, pp. 994-1003.

[4] J.M. Mendel, "Fuzzy logic systems for engineering: a tutorial," Proceedings of the IEEE, vol. 83, n³, March 1995, pp. 345-377.

[5] M.Y. Chow et al., Motor Incipient Fault Detection Using Artificial Neural Network and Fuzzy Logic Technologies, in Computer Aided Maintenance, Methodology and Practices. J. Lee, Ed.: Chapman Hall, 1996.

[6] M.Y. Chow, Methodologies of Using Neural Network and Fuzzy Logic Technologies for Motor Incipient Fault Detection. Singapore: World Scientific Publishing Co. Pte. Ltd., 1997.

[7] M.Y. Chow et al., Intelligent Motor Fault Detection, in Intelligent Techniques in Industry. L.C. Jain, Ed.: CRC Press, 1998

[8] H.J. Zimmermann, Fuzzy Set Theory and Its Applications. Kluwer Academic Publishers, 1991.

[9] P.V. Goode et al., "Neural/fuzzy systems for incipient fault detection in induction motors," Proceedings of the 1993 International Conference of the IEEE Industrial Electronics Society, Maui (USA).

[10] E. Ritchie et al., "Diagnosis of rotor faults in squirrel cage induction motors using a fuzzy logic approach," Proceedings of the 1994 International Conference on Electrical Machines, Paris (France), vol. 2, pp. 348-352.

[11] P.V. Goode et al., "A hybrid fuzzy/neural system used to extract heuristic knowledge from a fault detection problem," Proceedings of the 1994 IEEE World Congress on Computational intelligence, Orlando (USA), vol. 3, pp. 1731-1736.

[12] P.V. Goode et al., "Using a neural/fuzzy system to extract knowledge of incipient fault in induction motors Part I - Methodology," IEEE Trans. Industrial Electronics, vol. 42, n², April 1995, pp., 131-138.

[13] P.V. Goode et al., "Using a neural/fuzzy system to extract knowledge of incipient fault in induction motors Part II - Application," IEEE Trans. Industrial Electronics, vol. 42, n² 2 , April 1995, pp. 139-146.

[14] F. Filippetti et al., "A fuzzy logic approach to on-line induction motor diagnostics based on stator current monitoring," Proceedings of the 1995 IEEE International PowerTech Conference, Stockholm (Sweden), vol. EMD, pp. 156-161.

[15] N.M. Roehl et al., "Fuzzy ART neural network approach for incipient fault detection and isolation in rotating machines," Proceedings of the 1995 IEEE International Conference on Neural Networks, vol. 1, pp. 538-542.

[16] S. Altug et al., "Comparative analysis of fuzzy inference systems implemented on neural structures," Proceedings of the 1997 International Conference on Neural Networks, Houston (USA), vol. 1, pp. 426-431.

[17] S. Chun et al., "A fuzzy expert system for vibration cause identification in rotating machines," Proceedings of the 1997 IEEE International Conference on Fuzzy Systems, vol. 1, pp. 555-560.

[18] J. Boyce et al., "Pump motor vibration analysis and fault detection using artificial neural/fuzzy system," Proceedings of the 1997 International Conference on Maintenance and Reliability, Knoxville (USA), vol. 2, pp. 60.01-60.15.

[19] S. Caldara et al., "A fuzzy diagnostic System: application to linear induction motor drives," Proceedings of the 1997 IEEE Instrumentation and Measurement Technology Conference, Ottawa (Canada), vol. 1, pp. 257-262.

[20] M.Y. Chow et al., "Set theoretic based neural-fuzzy motor fault detector," Proceedings of the 1998 International Conference of the IEEE Industrial Electronics Society, Aachen (Germany), vol. 4, pp. 1908-1913.

[21] G. Goddu et al., "Motor bearing fault diagnosis by a fundamental frequency amplitude based fuzzy decision system," Proceedings of the 1998 International Conference of the IEEE Industrial Electronics Society, Aachen (Germany), vol. 4, pp. 1961-1965.
[22] M.E.H. Benbouzid et al., "A simple fuzzy logic approach for induction motors stator condition monitoring," in Proceedings of IEEEIEMDC'01 (International Electric Machines and Drives Conference), Cambridge, Massachusetts (USA), June 17-20, 2001.

[23] M.E.H. Benbouzid et al., "Induction motors faults detection and localization using stator current advanced signal processing techniques," IEEE Trans. Power Electronics, vol. 14, n 1 , January 1999, pp. 14-22

[24] R.R. Schoen et al., "Effects of time-varying loads on rotor fault detection in induction machines," IEEE Trans. Industry Applications, vol. $31, n^{\circ} 4$, July-August 1995, pp. 900-906.

[25] R.R. Schoen et al., "Evaluation and implementation of a system to eliminate arbitrary load effects in current-based monitoring of induction machines," IEEE Trans. Industry Applications, vol. 33, nº, November-December 1997, pp. 1571-1577.

[26] S.M.A Cruz et al., "Stator winding fault diagnosis in three-phase synchronous and synchronous motors, by the extended Park's vector approach," IEEE Trans. Industry Applications, vol. 37, n5, September-October 2000, pp. 1227-1233.

[27] M.E.H. Benbouzid et al., "Monitoring and diagnosis of induction motors electrical faults using a current Park's vector pattern learning approach," IEEE Trans. Industry Applications, vol. 36, n³, May-June 2000, pp. 730-735.

[28] P. Vas, Vector Control of AC Machines. Oxford: Clarendon Press, 1990.

[29] G.B. Kliman et al., "Methods of motor current signature analysis," Electric Machines \& Power Systems, vol. 20, n5, September 1992, pp. 463-474.

[30] A.M. Trynadlowski et al., "Comparative investigation of diagnostic media for induction motors: A case of rotor cage faults," IEEE Trans. Industrial Electronics, vol. 47, n5, October 2001, pp. 1092-1099.

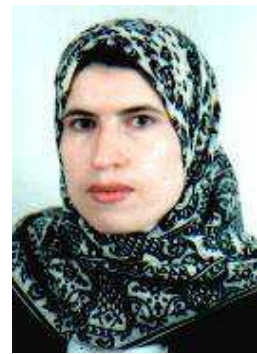

Fatiha ZIDANI was born in Batna, Algeria, in 1968. She received the B.Sc. and M.Sc. degrees both in Electrical Engineering, from the University of Batna, Algeria, in 1993 and 1996 respectively.

After graduation, she joined the University of Batna, Algeria, where she is a Teaching Assistant at the Electrical Engineering Institute. She is currently working towards a Ph.D. thesis on fuzzy control and diagnosis of induction motors.

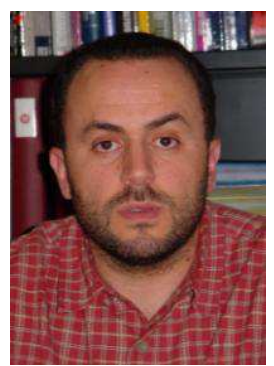

Mohamed El Hachemi BENBOUZID (S'92M'94-SM'98) was born in Batna, Algeria, in 1968 $\mathrm{He}$ received the B.Sc. degree in Electrical Engineering, in 1990, from the Electrica Engineering Institute of Batna University, Algeria; the M.Sc. and Ph.D. degrees both in Electrical and Computer Engineering, from the National Polytechnic Institute of Grenoble, France, in 1991 and 1994 respectively.

After graduation, he joined the University of Picardie "Jules Verne", France, where he is an Associate Professor of Electrical and Compute Engineering at the Professional Institute of Amiens. In November 2001, he received the "Habilitation à Diriger des Recherches" degree from the University of Picardie "Jules Verne". His current research interests include electric machines and drives control and diagnosis. 


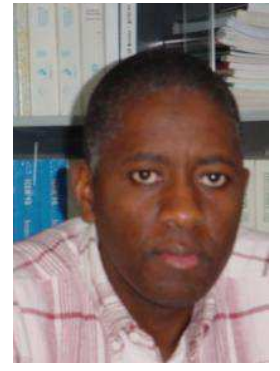

Demba DIALLO (M'99) was born in Dakar, Senegal, in 1966. He received the M.Sc. and Ph.D. degrees both in Electrical and Computer Engineering, from the National Polytechnic Institute of Grenoble, France, in 1990 and 1993 respectively.

From 1994 to 1999, he worked as a Research Engineer in the Laboratoire d'Electrotechnique de Grenoble, France, on electrical drives and active filters (hardware and software). In 1999 he joined the University of Picardie "Jules Verne" as an Associate Professor of Electrical engineering. His current area of research includes advanced control techniques and diagnosis in the field of ac drives.

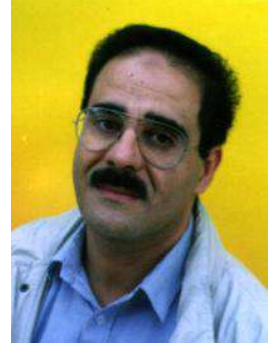

Mohamed Saïd NAIT SAID was born in Batna, Algeria, in 1958. He received the B.Sc. degree in Electrical Engineering, in 1983, from the National Polytechnic Institute of Algiers, Algeria and the M.Sc. degree in Electrical and Computer Engineering, in 1992, from the Electrical Engineering Institute of Constantine University, Algeria. In 1999, he received the Ph.D. degree in Electrical and Computer Engineering from the University of Batna, Algeria.

After graduation, he joined the University of Batna, Algeria, where he is an Associate Professor at the Electrical Engineering Institute. He is also the head of the Electrical Engineering Laboratory. His current research interests include electric machines and drives control and diagnosis. 